Thorax, 1977, 32, 129-133

\title{
Quantitative structural study of pulmonary circulation in the newborn with pulmonary atresia
}

\author{
SHEILA G. HAWORTH AND LYNNE REID
}

From the Department of Experimental Pathology, Cardiothoracic Institute, Brompton Hospital, London SW3

Haworth, Sheila G. and Reid, Lynne (1977). Thorax, 32, 129-133. Quantitative structural study of pulmonary circulation in the newborn with pulmonary atresia. The lungs of eight newborn infants who had died from pulmonary atresia were studied by quantitative morphometric techniques. It was established for the first time that the abnormal pattern of blood flow through the heart and great vessels in a fetus with pulmonary atresia is associated with impaired lung development as shown by arteries that are too few, too small, and with an abnormally thin muscle coat, although the distribution of muscle along the arterial pathway is normal. Differences between the cases in the degree of impairment of lung development could be detected and related to the degree of reduction in pressure and flow before birth in the individual case. Although blood flow through the pulmonary circulation is small before birth lung development seems sensitive to any further reduction.

In infants with either pulmonary atresia or stenosis who died during the perinatal period Naeye (1961) found a relative reduction in arterial medial area. In infants with pulmonary atresia who, because of a relatively large ductus arteriosus, survived slightly longer he reported a normal amount of muscle. He used a planimetric technique to relate the area of the media to that of the intima in small pulmonary arteries. Otherwise the state of development of the pulmonary circulation in pulmonary atresia has not been studied.

Patients with pulmonary atresia with an intact septum, or those with a ventricular septal defect who do not have a systemic arterial blood supply to the lung, must be operated on soon after birth if they are to survive. The state of the pulmonary circulation at birth will determine the response of the lung to a sudden increase in pulmonary arterial pressure and flow. Lung development was assessed in eight patients who died with pulmonary atresia during the first 28 days of life by reference to the number of preacinar arterial and venous branches, the multiplication of intra-acinar arteries, and the size and wall structure of both pre- and intraacinar arteries.

\section{Patients and methods}

CLINICAL FEATURES

Lung structure was examined in six patients with pulmonary atresia and an intact ventricular septum (IVS) and in two patients with pulmonary atresia and a ventricular septal defect (VSD). They all presented during the first 3 days of life and died within the first 28 days (Table 1). In all the clinical features were similar. Cyanosis was present either at birth or within 12 hours. The second heart sound was single in all. Four babies had the continuous murmur typical of a patent ductus arteriosus while three had a systolic murmur. One (case 8) had the clinical features of Down's syndrome. In all patients electrocardiography showed left axis deviation, and in all but case 8 the right ventricular forces were. of reduced amplitude in the right precordial leads.

In all the infants a chest radiograph showed diminished pulmonary vascular markings and an absent pulmonary conus. Only one (case 6) had cardiac enlargement, which was evident both before and after surgery. In all cases fine nodular markings were present in the lung periphery, but sparse. In case 6 , after a Waterston-Cooley anastomosis, the lung fields looked plethoric and the diffuse opacity of severe oedema developed rapidly.

Cardiac catheterisation showed that in all cases of pulmonary atresia with IVS (cases 1-6) right ventricular pressure was raised, varying between $7.98 \mathrm{kPa}(60 \mathrm{mmHg})$ and $21.28 \mathrm{kPa}(160 \mathrm{mmHg})$, and a right-to-left shunt at atrial level produced 
Table 1 Summary of pathological findings

\begin{tabular}{|c|c|c|c|c|c|c|}
\hline \multirow[b]{2}{*}{$\begin{array}{l}\text { Case } \\
\text { No. }\end{array}$} & \multirow[b]{2}{*}{$\begin{array}{l}\text { Ventricular } \\
\text { septum }\end{array}$} & \multirow{2}{*}{$\begin{array}{l}\text { Age at } \\
\text { death } \\
\text { (days) }\end{array}$} & \multicolumn{2}{|c|}{ Size of arteries } & \multirow[b]{2}{*}{$\begin{array}{l}\text { No. of } \\
\text { arteries }\end{array}$} & \multirow[b]{2}{*}{$\begin{array}{l}\text { Arterial } \\
\text { muscularity }\end{array}$} \\
\hline & & & Preacinar & $\begin{array}{l}\text { Intra } \\
\text {-acinar }\end{array}$ & & \\
\hline 1 & Intact & 1 & $\downarrow$ & $\downarrow$ & $\downarrow$ & $\downarrow$ \\
\hline 2 & Intact & 2 & $\downarrow$ & $\downarrow$ & $\downarrow$ & \\
\hline 3 & Intact & 2 & $\downarrow$ & $\downarrow$ & $\mathbf{N}$ & $\downarrow$ \\
\hline 4 & Intact & 2 & $\downarrow$ & $\downarrow$ & $\mathbf{N}$ & $\mathbf{N}$ \\
\hline 5 & Intact & 15 & $\downarrow$ & $\downarrow$ & $\downarrow$ & $\downarrow$ \\
\hline $6^{*}$ & Intact & 21 & $\mathbf{N}$ & $\mathbf{N}$ & $\downarrow$ & $\uparrow$ \\
\hline 7 & VSD & 4 & $\downarrow$ & $\downarrow$ & $\mathbf{N}$ & $\mathbf{N}$ \\
\hline 8 & VSD & 28 & $\downarrow$ & $\downarrow$ & $\downarrow$ & $\downarrow$ \\
\hline
\end{tabular}

$\mathbf{N}=$ Normal.

$\uparrow=$ Increase above normal.

$\downarrow=$ Decrease below normal.

* = Aortopulmonary anastomosis.

systemic arterial desaturation. Angiography in cases 1-5 showed a small right ventricular cavity ending blindly with dilated sinusoids in the right ventricular wall (type I pulmonary atresia: Greenwold et al., 1956). In case 6 the right ventricular cavity was larger and tricuspid regurgitation was present (type II). In cases 7 and 8 angiography showed pulmonary atresia with VSD and in case 7 corrected transposition of the great vessels. In all eight cases the intrapulmonary arteries appeared smaller than normal and were filled via the ductus arteriosus.

In case 6 a Waterston-Cooley anastomosis and pulmonary valvotomy were performed on the second day of life. This produced intractable heart failure and pulmonary oedema and on the 27th day, one day before death, the shunt and a patent ductus arteriosus were ligated. Shunt procedures were also performed in cases 1,2 , and 4 ; but two patients died during the operation and one (case 4) died four hours after surgery. Since only one patient (case 6) survived operation with an increase in pulmonary blood flow this case is described in the text as 'shunted'.

MÁTERIAL FOR PATHOLOGICAL STUDY

In six cases the right pulmonary artery and the left pulmonary vein were injected and in the remaining cases (case 3 and 6) both pulmonary arteries were injected.

The preparation of lung tissue and the techniques of quantitative analysis of lung structure were as described in a previous paper (Haworth and Reid, 1977).

\section{Results}

The structural findings are summarised in Table 1 and were similar in all eight patients whether or not the ventricular septum was intact. In all the ductus arteriosus provided the only blood supply to the lung. Examination of each specimen failed to reveal any large systemic arteries arising from the aorta to supply the lung, and on arteriography the bronchial arteries were not enlarged nor were any anastomoses seen between pulmonary and क bronchial circulations. On the specimen arterio- $\vec{\circ}$ grams and venograms the pulmonary arterial and venous branching patterns were normal.

In all seven untreated cases of pulmonary atresia the lumen diameter of the pre-acinar arteries and the external diameter of the intraacinar arteries were smaller than normal. In case $N$ 6 , where pulmonary blood flow had been increased $\vec{N}$ by an aortopulmonary anastomosis, the vessels were of normal calibre and possibly increased above normal in size at the level of the terminal bronchiolus.

In all eight cases of pulmonary atresia no background haze was present. This is normal at birth, $\vec{v}$ since intra-acinar vessels develop mainly after. birth (Hislop and Reid, 1973a). Microscopically, the proportion of lung volume occupied by arteries was also reduced except in case 5 . These findings were explained by a reduction, in five out of eight $\stackrel{\otimes}{0}$ cases, in the number of intra-acinar arteries per $\mathbb{D}$ unit area of microscopic lung field (Table 2). Since alveolar number was normal the alveolar/arterial ratio was greater than normal.

Table 2 Number of alveoli and arteries per unit area $\left(\mathrm{cm}^{2}\right)$ and alveolar/arterial ratio

\begin{tabular}{lrll}
\hline Case No. & $\begin{array}{l}\text { No. of } \\
\text { alveoli }\end{array}$ & $\begin{array}{l}\text { No. of } \\
\text { arteries }\end{array}$ & $\begin{array}{l}\text { Alveolar/arterial } \\
\text { ratio }\end{array}$ \\
\hline 1 & 13740 & 380 & $36 \cdot 2$ \\
2 & 11696 & 284 & $41 \cdot 2$ \\
3 & 14110 & 635 & $22 \cdot 2$ \\
4 & 14740 & 686 & $21 \cdot 5$ \\
5 & 12889 & 460 & $27 \cdot 9$ \\
$6 *$ & 16624 & 472 & $34 \cdot 3$ \\
7 & 14653 & 622 & $23 \cdot 6$ \\
8 & 10366 & 409 & $25 \cdot 3$ \\
Normal values at: & 8863 & & \\
Birth & 12722 & 668 & $18 \cdot 9$ \\
3 days & 13196 & 516 & $20 \cdot 3$ \\
4 weeks & 11315 & 529 & $25 \cdot 5$ \\
4 months & 115 & $22 \cdot 2$ \\
\hline
\end{tabular}

* Aortopulmonary anastomosis.

ASSESSMENT OF ARTERIAL MUSCULARITY Arteries less than $250 \mu \mathrm{m}$ in diameter In arteries less than $250 \mu \mathrm{m}$ in diameter percentage wall $\frac{\rho}{\Phi}$ thickness was below normal in five out of seven untreated cases and normal in the remaining two (Figure). In these seven cases muscle was present 
in arteries smaller than normal, evidently owing to reduced size of the arteries since muscle did not extend further along the arterial pathway than normal, as shown by the assessment of arterial structure in relation to the type of accompanying airway.

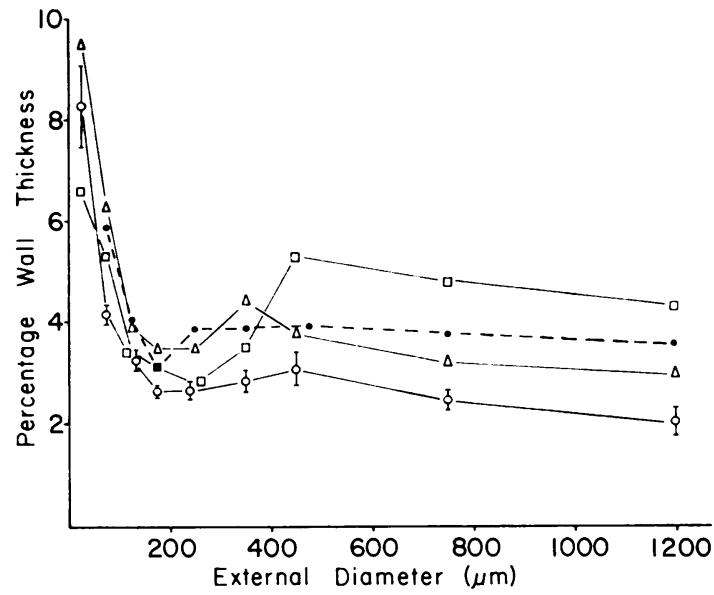

Figure Percentage wall thickness of small peripheral pulmonary arteries related to external diameter $(\mu \mathrm{m})$, showing reduction in muscularity in vessels of all sizes in cases with small ductus arteriosus, reduction in muscularity of arteries greater than $250 \mu \mathrm{m}$ in diameter in cases with relatively large ductus arteriosus and with aorto-pulmonary anastomosis, and medial hypertrophy in arteries larger than $250 \mu \mathrm{m}$ in diameter. $\bigcirc-O$ Mean of cases $1,2,4,5$, and 8 . $\Delta-\Delta$ Mean of cases 3 and $7 . \square-\square$ Case 6. - - - Normal 3 days. I SE.

Arteries more than $250 \mu \mathrm{m}$ in diameter Those five untreated cases in whom arteries less than $250 \mu \mathrm{m}$ in diameter were thin-walled showed an even greater reduction in wall thickness in vessels larger than $250 \mu \mathrm{m}$. In the other two untreated cases (cases 3 and 7) these larger arteries showed only a slight reduction in wall thickness, although this was more pronounced the larger the artery. Also in these two cases the number of intraacinar arteries was normal.

The fact that arterial muscularity and the number of arteries were almost normal in cases 3 and 7 suggests less functional disturbance of the pulmonary circulation in these than in the remaining five untreated cases. Pulmonary blood flow was probably greater here, since despite the difficulty of assessing the size of the ductus arteriosus after surgical intervention it was obviously larger in cases 3 and 7 than in the others, measuring $6 \mathrm{~mm}$ and $3 \mathrm{~mm}$ respectively. The external diameter was $2 \mathrm{~mm}$ or less in the remaining five cases.

After an aortopulmonary anastomosis in case 6 the findings were different. Wall thickness of arteries less than $250 \mu \mathrm{m}$ in diameter was normal, as in the untreated cases with a relatively large ductus arteriosus (cases 3 and 7). In arteries greater than $250 \mu \mathrm{m}$ an abnormally thick muscle coat had developed and at 28 days exceeded that found normally in the newborn infant (Figure). Muscle was also present in smaller arteries than is normal (Figure) and also, in contrast to all other cases of pulmonary atresia, muscle extended further into the acinus than is normal. Case 6 also differed from the untreated cases in that arterial size was normal, although arterial number remained as low in this as in the untreated cases.

Veins In pulmonary stenosis vein wall thickness was increased in vessels of all sizes: in pulmonary atresia the increase was less and seen only in the smaller veins.

\section{Discussion}

Since in pulmonary atresia the circulatory pathway through the heart and great vessels is abnormal during fetal life not surprisingly the structure of the pulmonary circulation is abnormal at birth. The size of pre- and intra-acinar arteries is reduced and there are fewer intra-acinar arteries than normal. Five patients died during the first 4 days of life, and so the changes can be assumed to have occurred in utero.

In pulmonary atresia Naeye (1961) reported a reduction in cross sectional area of the media in individual pulmonary arteries. This we have shown, but in addition we have demonstrated that despite the thinner wall muscle extends as far along the arterial pathway as in the normal lungthat is, to the level of the terminal bronchiolus. The reduction in muscularity is in the amount of muscle in normally muscular arteries but not in its extent. Naeye (1961) found a normal amount of pulmonary arterial muscle in cases of pulmonary atresia with a relatively large ductus, and we have confirmed this. It seems that to develop an arterial muscle coat of normal thickness before birth a certain level of blood flow or arterial pressure is required.

In the present series, whether or not the ventricular septum was intact, there was no evidence of either an enlarged bronchial arterial supply or of a collateral systemic arterial supply to the lung. Similarly, Naeye (1961) found no abnormality of the bronchial circulation arising either before or after birth in patients with pulmonary atresia or stenosis. In a series of children with tetralogy of Fallot Ferencz (1960a) found an enlarged bronchial circulation in two newborn infants as well as in the older children, and suggested that this sys- 
temic arterial supply to the lung could develop in utero. Such changes could not, however, be shown by Hislop and Reid (1973b), who studied older patients, applying a similar injection technique to that used in the present study.

Jefferson et al. (1972), in an angiographic study of patients with pulmonary atresia aged between 4 months and 16 years, described two types of arterial supply to the lung arising from the aorta or its branches-either a small number of large arteries, usually between two and five, or many small vessels. In both types the systemic arteries anastomosed with branches of the pulmonary artery at the hilum. Neither the 'large' nor the 'small' arteries were thought to be of bronchial origin. In their series the large arteries were present only when central pulmonary arteries were not, and this was thought to explain the persistence of primitive segmental arteries which arose originally from the paired dorsal aortae (Boyden, 1970). The 'small' arteries ran an intramediastinal course in the perihilar region before filling the intrapulmonary arteries, but they also were not considered to be bronchial in origin. The absence of any small arteries to the lung in the present series of cases suggests that these vessels are acquired. It seems that infants born with pulmonary valve atresia will not usually survive without treatment unless large systemic arteries perfuse the lungs. Multiple vessels probably appear later, in childhood, and in patients in whom at birth the pulmonary valve had been severely narrowed but not atretic.

Pulmonary blood flow is low after birth in pulmonary atresia, and the small size of both pre- and intra-acinar arteries suggests that even before birth pulmonary blood flow was abnormally low. The left ventricle in pulmonary atresia ejects the total cardiac output and so may generate a higher pressure than normal but (unlike the state of affairs in aortic atresia and stenosis) this pressure is probably not transmitted to the pulmonary circulation. In pulmonary atresia the discrepancy in size between the small right and left pulmonary arteries and their feeding vessel, the dilated aorta, is greater than normal, suggesting a considerable fall in pressure across these vessels during fetal life. Thus intrapulmonary arteries in cases of pulmonary atresia are possibly exposed before birth to a lower pressure than normal.

Although a low pulmonary arterial pressure may explain the reduced arterial muscularity increase in pulmonary arterial oxygen tension might also contribute. Fetal pulmonary vessels are known to respond to slight changes in oxygen tension of the perfusing blood (Lauer et al., 1965), which in pul- monary atresia is higher than normal because oxygenated placental blood mixes with deoxygenated systemic and pulmonary venous blood in the left ventricle. In aortic atresia and stenosis, despite a similar increase in oxygen tension, more smooth muscle develops than is normal. The reduction in arterial muscularity in pulmonary atresia is therefore more likely to be related to reduced pulmonary arterial pressure than to the increase in pulmonary arterial oxygen tension.

Reduced arterial muscularity may contribute to a low pulmonary vascular resistance because a thinner wall gives a larger lumen and it also diminishes the force of vasoconstriction. Both before and after birth a low pulmonary vascular resistance encourages flow of blood from the aorta to the pulmonary artery, a reversal of the normal direction.

The mechanism of the reduced number of arteries is not understood. It could arise from the reduction in pulmonary blood flow, since infants in whom arterial number was normal had a large ductus arteriosus and also had a normal arterial wall thickness. Recent studies have shown that banding the left pulmonary artery in the newborn pig leads to the development of fewer intra-acinar arteries than normal (Chung, personal communication). Perhaps a certain distending pressure is needed to ensure normal prenatal development of intra-acinar vessels, although this does not seem to be so in postnatal life since in older patients with tetralogy Hislop and Reid (1973b) found an increased number of peripheral arteries.

A reduction in arterial number implies a reduction in capacity of the pulmonary circulation. To accommodate an increase in blood volume in the normal lung, recruitment of additional channels is said to be more important than distension of channels already perfused (Maseri et al., 1972). If recruitment is impaired in pulmonary atresia because of a reduction in arterial number, a surgical increase in pulmonary blood flow in cases with pulmonary atresia might produce an inappropriate increase in pressure, thereby encouraging hypertrophy of vascular smooth muscle, as occurred in one infant in the present series. The smaller volume of the peripheral pulmonary arterial circulation might explain why newborn infants with pulmonary atresia are apt to develop postoperative oedema after an aortopulmonary anastomosis and later to develop obliterative pulmonary vascular disease (Ferencz, 1960b).

Both pre- and intra-acinar arteries are abnormally small in pulmonary atresia, but at this age the vessels are evidently distensible since in the one patient who had had an aortopulmonary ana- 
stomosis at 2 days dilatation had presumably occurred until the vessels were of normal size at death at 28 days of age. In contrast, Hislop and Reid (1973b) reported failure of the intrapulmonary arteries to increase in size in an older child of 5 years with tetralogy of Fallot in whom a clinically successful Blalock anastomosis was performed. In tetralogy of Fallot the arteries may become less distensible with increasing age. Hislop and Reid (1973b) found an abnormally thick arterial muscle coat in older patients with this condition.

These findings in the pulmonary circulation of patients with pulmonary atresia show that, as in aortic atresia and stenosis (Haworth and Reid, 1977), the pulmonary circulation is modified structurally by an abnormal pulmonary arterial pressure and flow during fetal life. Since in the normal fetus pulmonary flow is less than $6 \%$ of the combined ventricular output (Rudolph and Heymann, 1967) the presence of structural change in pulmonary atresia, a condition likely to produce an even smaller pulmonary blood flow, indicates how sensitive the pulmonary circulation is before birth to even small haemodynamic changes. This sensitivity is further emphasised by intra-acinar variation between the cases in the degree of arterial multiplication and muscularity, which presumably reflects minor differences in pulmonary blood flow and arterial pressure.

The structural changes in the lungs of newborn infants who died with pulmonary atresia, as with aortic atresia and stenosis (Haworth and Reid, 1977), show that abnormalities during fetal life in the circulatory pathway through the heart and great vessels alter structural development. In aortic atresia and stenosis probably an abnormally high prenatal level of pulmonary arterial pressure is associated with an increased number of intraacinar arteries and with increased arterial and venous muscularity, the muscle extending in both systems into smaller and more peripheral vessels than normal. In contrast, a reduction in pulmonary arterial pressure and flow before birth, as might occur in pulmonary atresia, is associated with fewer intra-acinar arteries than is normal, a reduction in arterial muscularity, and, in addition, abnormally small pre- and intra-acinar arteries. If the pulmonary circulation is normal at birth a postnatal increase in arterial pressure and flow, as in coarctation of the aorta with a patent ductus arteriosus and a ventricular septal defect, causes a rapid increase in arterial size and muscularity which is apparent within the first week of life.

We thank the physicians and surgeons of the
Brompton Hospital, London, and of the Deutsches Herzzentrum, Munich, Germany, for permission to use material from their cases.

This work was supported by the Wellcome Trust.

\section{References}

Boyden, E. A. (1970). The developing bronchial arteries in a fetus of the twelfth week. American Journal of Anatomy, 129, 357-368.

Ferencz, C. (1960a). The pulmonary vascular bed in tetralogy of Fallot. I. Changes associated with pulmonic stenosis. Bulletin of the Johns Hopkins Hospital, 106, 81-99.

Ferencz, C. (1960b). The pulmonary vascular bed in tetralogy of Fallot. II. Changes following a systemic-pulmonary arterial anastomosis. Bulletin of the Johns Hopkins Hospital, 106, 100-118.

Greenwold, W. E., DuShane, J. W., Burchell, H. B., Bruwer, A., and Edwards, J. E. (1956). Congenital pulmonary atresia with intact ventricular septum: two anatomic types. (Abstract). Circulation, 14, 945-946.

Haworth, S. G. and Reid, L. (1977). A quantitative structural study of the pulmonary circulation in the newborn with aortic atresia, stenosis or coarctation. Thorax, 32, 121-128.

Hislop, A. and Reid, L. (1973a). Pulmonary arterial development during childhood: branching pattern and structure. Thorax, 28, 129-135.

Hislop, A. and Reid, L. (1973b). Structural changes in the pulmonary arteries and veins in tetralogy of Fallot. British Heart Journal, 35, 1178-1183.

Jefferson, K., Rees, S., and Somerville, J. (1972). Systemic arterial supply to the lungs in pulmonary atresia and its relation to pulmonary artery development. British Heart Journal, 34, 418-427.

Lauer, R. M., Evans, J. A., Aoki, H., and Kittle, C. F. (1965). Factors controlling pulmonary vascular resistance in fetal lambs. Journal of Paediatrics, 67, 568-577.

Maseri, A., Caldini, P., Harward, P., Joshi, R. C., Permutt, S., and Zierler, K. L. (1972). Determinants of pulmonary vascular volume: recruitment versus distensibility. Circulation Research, 31, 218-228.

Naeye, R. L. (1961). Perinatal changes in the pulmonary vascular bed with stenosis and atresia of the pulmonic valve. American Heart Journal, 61, 586-592.

Rudolph, A. M. and Heymann, M. A. (1967). The circulation of the fetus in utero: methods for studying distribution of blood flow, cardiac output and organ blood flow. Circulation Research, 21, 163184.

Requests for reprints to: Dr. Lynne Reid, Department of Pathology, Bldg. G-9, Children's Hospital Medical Center, 320 Longwood Avenue, Boston, MA, 02115, USA. 